\title{
Introduction
}

\section{NEW PERSPECTIVES ON PSYCHOANALYTIC CLINICAL PROCESSES}

\section{Hanoch Yerushalmi ${ }^{1}$}

\section{REVISITING ANALYTIC CONCEPTS AMID A GLOBAL CRISIS}

From time to time, analytic therapists tend to re-examine their fundamental personal and theoretical perceptions, beliefs, and experiential knowledge of analytic processes. Currently, however, this mental action seems especially urgent amidst the massive volatile social, cultural, and political repercussions of the global COVID-19 pandemic. Our personal and public realities and our ways of living in them have dramatically changed-indefinitely. Moreover, some of the current challenges might change our lives beyond this global crisis and, therefore, analytic therapists need to revisit our conceptualization. To this end, this special issue of the American Journal of Psychoanalysis on current clinical issues in psychoanalysis offers new perspectives on human development, psychopathology, intrapsychic and intersubjective processes, and transference-countertransference relations. In this issue, various contemporary writers present their experiences, reflections, and theoretical suggestions regarding processes of change and personal growth within and outside the analytic process framework. While representing a diversity of analytic perspectives, the contributors to this issue are united in their dedication to introspective observation of their own and their patients' moment-to-moment responses and communications in the analytic space; to learn and formulate something meaningful about human motivations, aspirations, ideals, and processes of change.

Kernberg (2021) addresses the future of psychoanalysis amidst the emergence of competing therapeutic approaches and the criticism raised against its effectiveness while ignoring its enormous scientific and cultural contributions to society. Kernberg believes that what weakens

Address correspondence to Hanoch Yerushalmi, Ph.D., 48a Eder Street, 3475293, Haifa, Israel. 
psychoanalysis is its lack of a clear and comprehensive definition as a school of thought and practice that requires specific competencies. He also sees as problematic psychoanalytic training organizations that are all too often authoritarian in their approaches, and a general professional conflict between viewing psychoanalysis as a scientific enterprise versus a humanistic one. Given the field's historical developments, Kernberg stresses the importance of re-conceptualizing and integrating analytic theoretical and technical principles and embedding them in the network of neighboring areas such as neurobiology, sociology, and organizational and historical studies. In addition, Kernberg suggests specific structural changes in psychoanalytic institutes, including the development of relevant research and ties with academia and the wider community. He also advocates greater receptivity to other disciplines, such as philosophy, art, and religion, and to the integration of humanistic, existential, and scientific aspects into the theory and practice of psychoanalysis.

Ahumada (2021) believes that Freud foretold the future development of psychopathology from the neurotic to the borderline and autistic phenomena by stating that the external world is what endangers people and gives them satisfaction. Ahumada offers a broad perspective on the evolution of humans as a special species that developed an inner world consisting of instinct, object, self, and special mind-body capacities of emotionality and sociability. A prominent factor in the evolution of the self is the mutual mother-child relationship that gives the child a sense of protection and facilitates the child's self-reflectivity and self-recognition. Ahumada adds that traditional communities, including families characterized by mutuality and strong commitment, became dominated by contracts between people, which lack affectivity and reciprocity and invoke in people the delusion that they can create and recreate themselves and the world. Ahumada suggests that these recent cultural changes that intensified borderline disorder and autistic psychological conditions require amendment of the psychoanalytic process.

Civitarese (2021) describes Bion's grid as a map of unconscious emotional attitudes of both patient and analyst, used primarily to construct their here and now, which can lead to either progression or regression. From this perspective, the individual analytic work is viewed as group work that concentrates on emotional transformations in the here and now of the analytic session. Furthermore, analytic materials are viewed as a dream text, capable of revealing the intersubjective reality and the analytic dyad's emotional atmosphere. Civitarese's examples deeply illustrate that the emerging analytic material is a dream shared by the patient and the analyst that expresses the emotional truth. He also illustrates how Bion's theory 
might be linked with the theories of Klein and Winnicott to construct the multi-layered analytic reality.

Ferro (2021) examines the interrelationships between the concepts of play, negative capability, and other forms of negativity in the works of Bion, Winnicott, and Greene, which he describes as fundamental to contemporary psychoanalysis. Ferro explains that, in recent decades, analysts moved away from analyzing the analytic content and discovering the patients' childhoods toward struggling to develop tools for narrating their experiences. He elaborates specifically on Bion's concept of negative capability and describes it as the ability to tolerate enigma, mystery, the unknown, and uncertainty and as an indispensable medium for play. When holding a position of negative capability, therapists can play and engage in the mental activity of alphabetizing different forms of negativity weaved into our experience and thereby expand and enrich our minds.

Harris, et al. (2021) tell the stories of several analytic therapies, during the pandemic, with patients of different ages and life circumstances. The authors present transference-countertransference manifestations in these analytic environments and describe the patients' and therapists' struggles with their external and internal realities. Harris and her colleagues view both participants in the analytic space as experiencing après-coup phenomena that transform past dissociated experiences into traumatic experiences. The writers suggest that analytic processes cannot be understood without regarding the mental, cultural, and natural ecologies in which they occur.

Yerushalmi (2021) compares the listening of the supervisor to the supervisee's narrative with the therapist's process of listening to the patient's associations. He suggests that focusing on the musical aspect of the supervisee's narrative, such as intonations and rhythms, helps construct unsymbolized meanings and identify the patient's voice concealed in the supervisee's voice. Yerushalmi proposes the echo chamber metaphor to describe the supervisors' implicit device of attending to the musical aspect of the therapeutic narrative in parallel to the metaphors of hovering attention and dreaming. The special characteristics of the echo chamber are used to explain its capacity to facilitate the discovery of hidden meanings and finding the uniqueness of each therapeutic narrative.

Despite the diversity of their vantage points, all the contributors highlight changes in how one views the process of clinical psychoanalysis. Kernberg suggests that it may be difficult to integrate insights from related areas of study and thought such as neurobiology, sociology, art, and philosophy into the understanding of internal changes. Ferro mentions the transformation in analytic thinking from reconstructing childhood experiences and deciphering analytic content to concentrating on the analytic dyad's joint endeavor 
to create an analytic narrative. Civitarese points to the current emphasis in psychoanalysis on emotional transformations, rather than organizing patients' past experiences in the here and now of the analytic process. Harris et al. highlight contemporary therapists' need to include the patient's and the therapist's mental, social, and natural ecology contexts in their basic analytic consideration of clinical issues. Ahumada stresses the transition of the theoretical and clinical emphasis from the neurotic toward the borderline and autistic conditions. Yerushalmi reflects the change in analytic thinking by highlighting the search for meanings in the unsymbolized aspects of the discourse both in analysis and supervision.

The analytic process emerges from this collection of articles as a collaborative endeavor to create a change-promoting space in which both partners live through transforming experiences and discover new meanings of their own and their partners' emotional responses. According to these theoretical contributions, the patient and the therapist can achieve these analytic goals if they develop the capacity to tolerate the unknown and the uncertain, become receptive to each other's emotional states, and engage in a joint reflective process on their shared lived transference-countertransference experiences. This perspective appears to resonate with Ogden's (2019) description of a recent shift in psychoanalysis from the epistemological perspective, characterized by the struggle to deepen the understanding of unconscious processes, toward the ontological perspective, characterized by the pursuit of experiencing aliveness and creativity within the analytic space.

One theorist who manifests this development in analytic thinking and practice and who represents this shift in psychoanalysis is Eigen (2012). He elaborates on the significance of the analytic dyad's experiences of shared regressive states or "shared-madness" (p. 1457). Eigen, who draws on Winnicott, suggests that the most significant analytic experiences are the transient regressive states, shared by the two analytic partners, and the recovery from these states. These experiences are laden with reconstructions of traumatic and disintegrating past experiences characterized by loneliness, madness, and the sense of breakdown. Eigen explains that whereas using an object teaches us that the world can survive us, recovering from madness teaches us that we can survive ourselves. In the same vein, VanDerHeide (2012) suggests that, for patients, undergoing and surviving disintegrating experiences of anxiety and madness together with the therapist holds healing power. The healing element emanates from the fact that when patients believe that their experiences are distinctly irregular, they feel sequestered from the rest of the world, "different, relationally inadequate, misunderstood, socially ineffective, unacceptable, and misfit" (p. 383). Contrarily, when sharing such experiences with the therapists, the 
patients experience what Stolorow (2007) describes as self-validating "existential kinship-in-the-same darkness" (p. 50).

\section{INDIVIDUAL AND DYADIC ANALYTIC DEVELOPMENTAL PROJECTS}

Experiencing shared regressive states might disrupt the analytic partners' sense of safety and wellbeing when they become overwhelmed by reconstructions of past traumatic experiences and feel confusion, loss, and anxiety. Notwithstanding these emotional dangers, the partners are usually ready to plunge into these regressive experiences because of a powerful internal impetus to grow personally. The notion of the impetus to grow draws on Kohut's (1982) statement that we all share a "developmental forward move" to actualize our "right to unfold and to be different" (p. 402) and on Bollas' (1992) suggestion that we share a "destiny drive," which means an "urge to develop the form of one's private idiom" ( $p, 71)$. According to Loewald (1960), this urge to grow propels us to envision ourselves in the future and create what he called "future-self" (p. 20). However, envisioning one's future self entails searching for ways to actualize the envisioned self and become who one is and to construct an inner plan to organize this effort.

The potential strength, cohesiveness, and effectiveness of such a plan seems to depend on one's connectedness with one's core sense of self with its ideals and passions and one's capacity to negotiate one's needs, yearnings, and passions with the world. Usually, such a plan remains unconscious because it is conjured mostly by intuitive and spontaneous inner processes concealed from the external world. The existentialists suggested a term to describe this plan: "fundamental project of being." They explained that the fundamental project reflects one's future-oriented self, implicitly guides one in how to "hurl" oneself into the future, and organizes one's choices of actions and positions (Tulloch, 1952, p. 37). Crowell (2012) adds that the fundamental personal project is a mental entity responsible for creating one's unique style of self-presentation and arranging the meaning-making process of internal and external phenomena.

The processes described above of envisioning one's self in the future and constructing one's fundamental personal project of being are intrinsic and unique to each person, but might also apply to processes of the analytic dyad as a group of two. Thus, within the analytic space, the participants, who become involved in an intensive and growth-promoting interaction, jointly create an ever-changing intersubjective configuration that Stern (1985, p. 10) referred to as "we-self," which needs validation and expression just like the individual self. Fişek (2010) suggests that this 
configuration cultivates in the analytic partners a "simultaneous sense of being oneself and being one-with" (p. 57). Baranger and Baranger (2008) believe that it becomes highly central to the analytic endeavor and that "neither member of the analytic couple can be understood without the

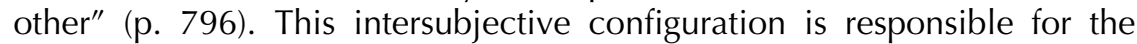
analytic dyad's unique shared goals, values, perceptions, symbols, and meaning system.

From this perspective, parallel to creating the personal future-self, the partners in each analytic dyad seem to envision their future we-self and imagine how it will affect their way of being who they are as an analytic couple. Similar to the development of the individual future-self, the analytic partners apparently develop an inner plan to actualize their future we-self and become who they are as a cohesive "intersubjective unit," what Cassorla (2001) called an "intersubjective unit" (p. 1158). In existential terms, this implicit joint plan might be described as the analytic dyad's fundamental shared-project of being. Like the individual project, the analytic dyad's shared project organizes and gives meaning to the participants' joint choices of actions and positions on matters that concern them both as an intersubjective unit. Among these shared positions are ways of processing and integrating their shared experiences, forming a shared world view, and presenting themselves as a cohesive intersubjective unit to others, including supervisors or colleagues. We can assume that the partners' shared fundamental project is neither explicit nor deliberate, in parallel with the individual fundamental project. Nonetheless, it is organized and patterned and, therefore, other professionals who are committed to following the evolution of the dyad's therapeutic relationship can identify it as it emerges from the therapist's narrative.

Constructing and formulating the shared dyadic fundamental project might not be easy because this construction includes elements of both analytic partners who co-created and shaped it mostly through subtle nonverbal communications. However, existentialists believe that, in contrast to one's original personal fundamental project chosen spontaneously and pre-reflectively early on in life, one can modify one's fundamental project only after considerable reflection on it and subsequent awareness of the advantages and flaws for one's existence (Engels, 2014). Therefore, it seems important to formulate each analytic dyad's fundamental shared project, with or without the help of colleagues or supervisors, so that the participants can replace it with an updated fundamental project when it is not compatible with their current state of we-self.

Furthermore, it seems important to formulate this shared fundamental project to strengthen the partners' sense of direction and purpose and to achieve better congruity between them when they struggle to actualize their 
shared future self. This notwithstanding, analytic partners too often find themselves hauling the analytic process in opposite directions, requiring them to negotiate their contradictory ways to construct their we-self. Therefore, constructing and formulating their fundamental shared project might help them to refine their moment-to-moment decision regarding the focus of their joint attention, whether to plunge into shared regressive states or to struggle to recover from them, whether to undermine their shared understandings and conclusions or to stabilize and consolidate their jointly reached conclusions.

https://doi.org/10.1057/s11231-021-09309-8

\section{NOTES}

1. Hanoch Yerushalmi, Ph.D. is a clinical psychologist in Israel, professor emeritus at the Department of Community Mental Health, University of Haifa, Israel, a Consulting Editor in the journal Psychoanalytic Social Work, USA, and a member of the British Association for Psychoanalytic and Psychodynamic Supervision. He has formerly been the Director of the Student Counseling Center director and a Senior Lecturer at the Hebrew University in Jerusalem. Prof. Yerushalmi served as a consultant to psychotherapy centers in Israel, the USA, and Central America and published numerous articles on relational psychoanalytic therapy, supervision and therapists' development, crisis and growth, and psychiatric rehabilitation.

\section{REFERENCES}

Ahumada, J. L. (2021). Unbridled! Thoughts on times of self-begetting and violence. American Journal of Psychoanalysis, 81(3).

Baranger, M., \& Baranger, W. (2008). The analytic situation as a dynamic field. International Journal of Psycho-Analysis, 89(4), 795-826.

Bollas, C. (1992). Being a character. Psychoanalysis and self experience. London: Routledge.

Cassorla, R. M. (2001). Acute enactment as a 'resource' in disclosing a collusion between the analytical dyad. International Journal of Psycho-Analysis, 82(6), 1155-1170.

Civitarese, G. (2021). Bion's graph of "In search of existence". American Journal of Psychoanalysis, 81(3).

Crowell, S. G. (2012). Sartre's existentialism and the nature of consciousness. The Cambridge companion to existentialism (pp. 218-219). Cambridge, UK: Cambridge University Press.

Eigen, M. (2012). On Winnicott's clinical innovations in the analysis of adults. International Journal of Psycho-Analysis, 93(6), 1449-1459.

Engels, K. S. (2014). Schopenhauer's intelligible character and Sartre's fundamental project. Idealistic Studies, 44(1), 101-117. https://doi.org/10.5840/ idstudies201521021 
Ferro, A. (2021). Negative capabilities, play and the negative. American Journal of Psychoanalysis, 81(3).

Fişek, G. O. (2010). Relationality, intersubjectivity, and culture: Experiences in a therapeutic discourse of virtual kinship. Studies in Gender and Sexuality, 11(2), 47-59.

Harris, A., Csillag, V., Cutner, N., Freeman-Carroll, N., Mayson, S. J., \& Rufino, M. (2021). Clinical life in the context of the pandemic. American Journal of Psychoanalysis, 81(3).

Kernberg, O. (2021). Challenges for the future of psychoanalysis. American Journal of Psychoanalysis, 81(3).

Kohut, H. (1982). Introspection, empathy, and the semi-circle of mental health. International Journal of Psycho-Analysis, 63, 395-407.

Loewald, H. W. (1960). On the therapeutic action of psychoanalysis. International Journal of Psycho-Analysis, 41, 16-33.

Ogden, T. H. (2019). Ontological psychoanalysis or "What do you want to be when you grow up?" The Psychoanalytic Quarterly, 88(4), 661-684. https://doi.org/10. 1080/00332828.2019.1656928

Stern, D. N. (1985). The interpersonal world of the infant: A view from psychoanalysis and developmental psychology. New York: Basic Books.

Stolorow, R. B. (2007). Trauma and human existence: Autobiographical, psychoanalytic, and philosophical reflections. New York: The Analytic Press. 2008.

Tulloch, D. M. (1952). Sartrian existentialism. The Philosophical Quarterly, 2(6), 31-52.

VanDerHeide, N. (2012). Can you hear me now? Twinship failure and chronic loneliness. International Journal of Psychoanalytic Self Psychology, 7(3), 369-390.

Yerushalmi, H. (2021). On supervisors' listening. American Journal of Psychoanalysis, 81(3).

Publisher's Note Springer Nature remains neutral with regard to jurisdictional claims in published maps and institutional affiliations. 